\title{
CHEMICAL COMPOSITION OF URINARY TRACT STONES: EXPERIENCE IN AMEDICAL COLLEGE HOSPITAL, IN DHAKA
}

\author{
SUDIP DAS GUPTA ${ }^{1}$, MANZOOR-UL-MAHBUB ${ }^{1}$, AFROZA GHANI $^{2}$, MOHAMMED MIZANUR RAHMAN $^{1}$, \\ MD. ZAHURUL HAQUE ${ }^{1}$
}

${ }^{1}$ Department of Urology, Sir Salimullah Medical College, Dhaka, Dhaka, Bangladesh, ${ }^{2}$ Department of Gynae, Shaheed Suhrawardy Medical College, Dhaka, Bangladesh

\begin{abstract}
s
Objective: To find out the chemical composition of urinary tract stones in patients attending our hospital.

Methods: A cross sectional hospital based study was conducted among 140 patients from October 2011 to September 2014 in SSMC \& MH. The study included all patients of either gender and all ages who were diagnosed to have urinary tract stones and were managed in our hospital. Chemical analysis of stones were performed on stones, fragments, gravel's passed spontaneously, or retrieved from endourological intervention or after ESWL or open surgery. Results were reviewed and analyzed with the help of SPSS17.

Result: Out of 140 patients about one third (31.4\%) were female and two thirds were (68.6\%) male. Most of the patients belong to age group 40-50 years. Mean age of the patients was 43.74 years with standard deviation of 10.28 years. $20 \%$ of the patients have recurrent stones. By the type of symptoms all of the patients had loin or back pain. One third of the patients had (36.7\%) calcium oxalet stones, more than one fourth of respondents (27.1\%) had mixed stones and $12.9 \%$ had magnesium, ammonium phosphate stones. Calcium containing stones were the most(60\%).

Conclusion: Calcium containing stones constitute the most common variety of urinary tract calculi in our local population.
\end{abstract}

Key words: Urolithiasis, Chemical composition of stone

Bangladesh J. Urol. 2015; 18(1): 8-11

Introduction:

Urolithiasis is the $3^{\text {rd }}$ most common affliction of urinary tract. It has plagued human since the earliest records of civilization. Its recurrent rate also warrants a great attention for the wellbeing of the patient. Without follow up and medical intervention stone recurrence rate can be as high as $50 \%$ within 05 years[1]. The distribution of urolithiasis varies differently across the world. High incidence areas are Scandinavian countries, Mediterrenanian, British Isles, Northern Australia, central Europe, parts of Malaysia, China, Pakistan and Western India[2]. Though there is no data but urolithiasis are most common problem in Bangladesh because of

Correspondences: Sudip Das Gupta, Department of Urology, Sir Salimullah Medical College, Dhaka, Bangladesh. E-mail: sudipuro@gmail.com geographical location, economic and dietary factors, dehydration, exposure to heat and possible genetic factor. Male to female ratio is $2: 1$ and peak incidence is observed in $2^{\text {nd }}$ or $3^{\text {rd }}$ decade of life[3]. Urinary calculi may have various compositions which includes calcium oxalate, uric acid, struvite, calcium phosphate and cystine. There are other less common stones like xanthine and drug-related stones as well[1]. Identification of stone composition is a sensitive tool for accurate treatment of stone diseases and for future stones, for prophylaxis thereby increasing quality of life[4]. From stone analysis clinician identifies causes of stone formation and thus helps in pharmacological and dietary treatment of identified metabolic abnormalities to 
decrease the morbidity and hospital related expense of the patients $[4,5]$. The study was carried out to find the chemical composition of urinary tract stones in patient attending our hospitals.

\section{Material and Method:}

The study included 140 stones obtained by surgical intervention (URS, PCNL, Open surgery) and medical expulsive therapy of urolithiasis patients attended at Sir Salimullah Medical College Mitford Hospital, Dhaka, Bangladesh during period of October, 2011 to September, 2014. The data was collected from the ward and out patients department of Urology. The stones obtained were sent to the chemical pathology laboratory of Dhaka University. These stones were washed with the distilled water to remove the debris, dried completely and weighed. The stones were triturated, the powdered form was mixed with distilled water in a graduated tube to make it up to $50 \mathrm{ml}$. Then the sample was analyzed by using Fourier transform infrared spectroscopy technique (FT-IR).

\section{Results:}

Total 140 samples of stone were analyzed during period of October, 2011 to September, 2014 as per inclusion criteria. Most of the patients belonged to age group 4050 years. Mean age 43.74 with standard deviation of 10.28 years.

Table-I

Age distribution of the patients.

\begin{tabular}{lcc}
\hline Age in years & Frequency & Percentage \\
\hline $20-30$ & 16 & 11.43 \\
$30-40$ & 36 & 25.71 \\
$40-50$ & 58 & 41.43 \\
$50-60$ & 26 & 18.57 \\
$>60$ & 4 & 2.86 \\
\hline Total & 140 & 100.00 \\
\hline
\end{tabular}

Of the 140 patients about one third (31.4\%) were female and two thirds ( $68.6 \%$ ) were female with male female ratio of 2.2:1.

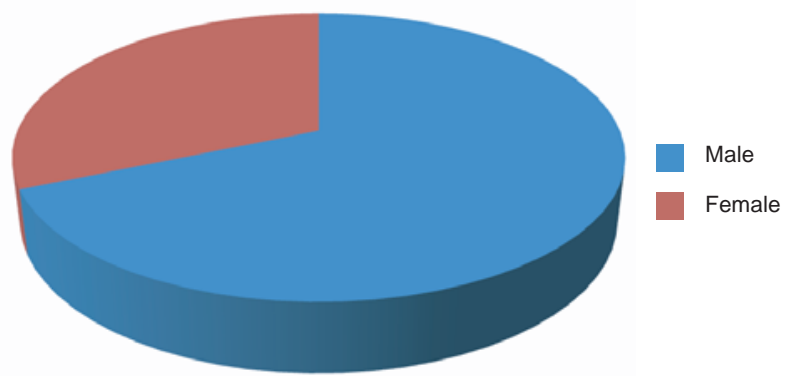

Fig.-1: Frequency of gender distribution of Urolithiasis patients.
One third of the patients (37.14\%) had calcium oxalate stones $80 \%$ of them were calcium oxalate monohydrate, $20 \%$ calcium oxalate dihydrate. Calcium phosphate stone constitute $22.86 \%, 27.14 \%$ stones were mixed stone and $12.86 \%$ magnesium, ammonium phosphate stones. Calcium containing stones were the most.

Table-III

Frequency of stones by composition.

\begin{tabular}{lcc}
\hline Composition of stones & Frequency & Percentage \\
\hline Calcium Oxalate & 52 & $37.14 \%$ \\
Calcium Phosphate & 32 & $22.86 \%$ \\
Mixed & 38 & $27.14 \%$ \\
Magnesium Ammonium & 18 & $12.86 \%$ \\
Phosphate (MAP) & & \\
Total & 140 & $100 \%$ \\
\hline
\end{tabular}

\section{Discussion:}

In Bangladesh exact incidence of the diseases is not known but may be regarded as the endemic zone for stone diseases. As our hospital lies in the centre of the country so patients come from the many parts of the country. Chemical analysis of the stones presented in the year from 2011 to 2014 has been discussed in this study.

Mean age was 43.74 years, with insignificant sex difference, 44.20 and 43.28 years in males and females respectively. Joul[6] reported mean age of 45years, whereas Shokouhi[7] found the mean age to be 40.5 years. The male and female mean ages was also in close proximity to Shokouhi which he reported to be 42.2 and 39.8 years for males and females respectively. In our study almost $78 \%$ of the patients were ranging between 20 to 50 years of age. This shows that renal stones affect the working age group. The male female ratio was 2.2:1 which was consistent to that of reported by Shokouhi et al[8]. Male are more sufferer than female may be due to their larger muscle mass or other unknown gender related factors. Thus the daily breakdown of tissue results in increased metabolic waste and a predisposition of stone formation. The other more significant cause may be due to of the male urinary tract being more complicated than female[9].

Kidney stones result when urine becomes too concentrated and substances in the urine crystallized to from stones. Besides dietary factor, the most common cause of renal stone formation is not drinking enough water. Excessive consumption of meat protein leads to 
a marked increase in renal stones formation as it causes over acidification of urine which leads to increase excretion of oxalate, calcium, and uric acid as well as decrease the excretion of citrate - that provides protection against stone production.

Urinary calculi are usually heterogenous, and all available methods of crystal identification have limitations. A total of $80-90 \%$ of human urinary stones are made of calcium salts. It is pertinent to know the composition of various parts of a stone, for instance the stone surface and the center. Some calculi contain a clearly defined nucleus or initial calculus and may consist of the same material as the bulk of the stone. In other cases the central core may consist of different material to the bulk of the stone. It is possible for any one of the four types of the crystal to be found as a surface or as secondary deposits. Here our findings corroborate the work done by Elliot, that the most common secondary and the peripheral deposits were COD and calcium phosphate, respectively. Complete stone treatment includes both its removal and prevention against recurrence. To prevent stone recurrence, one must be able to detect underlying metabolic abnormality and know the stone composition. Previous stone history aids in making the differential diagnosis. If the patient has had prior calculus and the crystallographic analysis has shown predominantly. Urinary calculi are usually heterogenous, and all Urinary calculi are usually heterogeneous and all available methods of crystal identification have limitations.

A total of $80-90 \%$ of human urinary stones are made of calcium salts. It is pertinent to know the compositionof various parts of a stone, for instance the stone surface and the center. Some calculi contain a clearly defined nucleus or initial calculus and may consist of the same material as the bulk of the stone. In other cases the central core may consist of different material to the bulk of the stone. It is possible for any one of the four types of the crystal to be found as a surface or as secondary deposits. Here our findings correlate the work done by Elliot, that the most common secondary and the peripheral deposits were COD and calcium phosphate, respectively[10].

Complete stone treatment includes both its removal and prevention against recurrence. To prevent stone recurrence, one must be able to detect underlying metabolic abnormality and know the stone composition. Previous stone history aids in making the differential diagnosis. If the patient has had prior calculus and the crystallographic analysis has shown predominantly one element, then it is likely that the next stone will be of the same type. Ljunghall and Hedstrand, in an epidemiological study, reported an approximately $50 \%$ natural recurrence after 5 years. As early as 1986, the annual recurrence rate after ESWL (consider stone-free rate at 3 months) was reported at $8 \%$. Recurrence after surgical intervention reported by Sutherland, was $40 \%$ after 11 years[11]. Stone metaphylaxis reduces the recurrence rate by some $40 \%$. Medical treatment could lower the recurrence rate after ESWL, endo-urological procedures, and open surgery[12]. Hence, complete metabolic evaluation and stone composition, especially in the high-risk group, is integral to the selection of the most appropriate intervention to prevent kidney stone recurrence[13]. For this reason chemical analysis of stone is a part of stone treatment in our centre and in this study by stone analysis it was found thatone third of the patients $(37.14 \%)$ had calcium oxalate stones $80 \%$ of them were calcium oxalate monohydrate, $20 \%$ calcium oxalate dihydrate. Calcium phosphate stone constitute $22.86 \%, 27.14 \%$ stones are mixed stone and $12.86 \%$ magnesium, ammonium phosphate stones. Calcium containing stones were the most.

\section{Conclusion:}

Present data indicate that the urinary stone structure and composition in Bangladesh is different from that of the Westernworld. Calcium oxalate monohydrate stones predominate. Even the majority of staghorn stones are made of oxalates. These stones are hard to break and have different metabolic causes and origins.It is necessary to know the stone compositionbefore opting for treatment techniques involving fragmentation(ESWL, laser). It is also essential to know the stone composition during the treatment of this disease, which has a potential of recurrence as high as 50\% at5 years, to institute adequate prophylaxis to ensure less morbid and more cost-effective treatment of urinary stone disease.

\section{Conflict of Interest : None Declared}

\section{References:}

1. Marshall L. Stoller MD. Urinary stone disease, in McAninch JW \& Leu TF. Smith \& Tanagho's General Urology. $18^{\text {th }}$ edition. Mc Graw Hill: Lange LANGE; 2013; 249-279.

2. Abbagani S, Gundimeda SD, Varre S, Ponnala D, Mundluru HP. Kidney Stone Disease: Etiology and Evaluation. IJABPT. May-July 2010; 1(1): 175-182.

3. Siddique EH, Abdul Munim, Siddiqui S and Shah N. Urolithiasis. Presentation and ultrasonographic evaluation. Professional Med J July-Sep 2011; 18 (3): 380-385. 
4. Sinno K, Boyce WH and Resnick MI: Childhood urolithiasis. J Urol 1979; 121: 662.

5. Holmes RP, Goodman HO, Assimos DG. Contribution of dietaryoxalate tourinary oxalate excretion. Kidney Int'I 2001; 59:270-6.

6. Joual A, H Rais, R. Rabii, M. El Mrini and S. Benjelloun. Epidemiology of urinary lithiasis. Ann. Urol. 1997; 31(2): 80-83.

7. Shokouhi B, Gasemi K, Norizadeh E. Chemical compositionand pidemiological risk factors of urolithiasis in Ardabil Iran.Research Journal of Biological Sciences 2008; 3(6): 620-626.

8. Joual A, H Rais, R. Rabii, M. El Mrini and S. Benjelloun. Epidemiologyof urinary lithiasis. Ann. Urol. 1997; 31(2): 80-83.

9. Pandeya A,Prajapati R, Panta P and Regmi A. Assessment ofkidney stone and prevalence of its chemical compositions. Nepal Med Coll J 2010; 12(3): 190-192
10. Elliot JS. Structure and composition of urinary calculi. J. Urol. 1973; 109: 82-3.

11. Sutherland JW. Recurrence following operative interventionof upper urinary tract stones. J. Urol. 1982; 27: 472-4.

12. Strohmaier WL. Socioeconomic aspects of urinary calculiand metaphylaxis of urinary calculi. Urologe A. 2000; 39: 166-70.

13. Aurora AL, Taneja OP, Gupta DN, Aurora AL, TanejaOP, Gupta DN. Bladder stone disease of childhood. I.An epidemiological study. Acta Paediatr. Scand. 1970; 59: 177-84.

14. Ljunghall $\mathrm{S}$, Hedstrand $\mathrm{H}$. Epidemiology of renal stonesin middle-aged male population. Acta Med. Scand. 1975; 197: 439-45.

Abbreviations:

COD: Calcium Oxalate dihydrate

ESWL: Extra corpored shockwave lithotripsy. 